\title{
First report on the presence of Alloxan in Bleached Flour by LC-MS/MS Method
}

\author{
Vita Giaccone', Gianluigi Maria Lo Dico', Licia Pantano', Gaetano Cammilleri', Valentina Cumbo', Antonio \\ Vella', Francesco Giuseppe Galluzzo', Ilaria Rizzuto', Barbara Randisi', Giulio Bagnato', Andrea Pulvirenti² \\ \& Andrea Macaluso' \\ Istituto Zooprofilattico Sperimentale della Sicilia “A. Mirri”, Via G. Marinuzzi 3, 90129 Palermo, Italy \\ ${ }^{2}$ Dipartimento di Scienze della Vita, Università degli Studi di Modena e Reggio Emilia, Via Università 4, 41121 Modena, Italy
}

\begin{abstract}
S
Alloxan is a ketone with a low molecular weight and neutral functional groups. In this work the presence of Alloxan in bread, pastry and cake bleached flour was investigate in order to verify possible risk for consumers related to the use of chemicals for flour bleaching.
\end{abstract}

KEY WORDS

Alloxan; UHPLC MS/MS; toxicology.

Received 22.11.2019; accepted 10.12.2019; published online 20.12.2019

Proceedings of the 4th International Congress on Biodiversity "Man, Natural Habitats and Euro-Mediterranean Biodiversity", November 17th-19th, 2017 - Malta

\section{INTRODUCTION}

Alloxan is an oxygenated pyrimidine synthesized by uric acid oxidation that can be found in hydrated form. It was found to have toxicological effects on pancreatic b-cells leading to diabetogenic action, therefore (Pincus, 2013) is commonly employee for the development of Type-I Diabetes Mellitus in animal models (Carvalho et al., 2003). Alloxan also demonstrated to have a carcinogenic action in rats and fishes; furthermore, it can induce adenohypophysis cancer in mices (Suganuma et al., 1993). The aim of this work is to prove the presence of Alloxan in bleached flour, given the absence of data in literature on the relative toxicity of this molecule in bakery products. A selective UHPLC MS/MS method using precolumn derivatization was developed for the determination of Alloxan in flours.

\section{MATERIAL AND METHODS}

A total of 175 bleached flour samples were col- lected from manufacturers and local market of Sicily (Southern Italy). All the samples considered in this study were randomly collected by choosing different texture and size of granulation: 62 bread flour (slightly coarse), 55 pastry flour and 58 cake flour (smooth and fine), respectively. $2 \mathrm{~g}$ of the homogenized flour samples were weighed in a polypropylene centrifuge tube and spiked with 200 $\mathrm{ml}$ of Alloxan working solution at $10 \mathrm{mg} \mathrm{mL} 1$ in Hydrochloridric acid $0.1 \mathrm{M}$ to obtain a concen- tration of $1 \mathrm{mg} \mathrm{kg} 1$. Every sample was mixed and allowed to rest for $15 \mathrm{~min}$. Subsequently, $10 \mathrm{~mL}$ of hydrochloride acid $0.1 \mathrm{M}$ were added in the tube and then mixed for $1 \mathrm{~min}$. The tube was vigorously centrifuged for $10 \mathrm{~min}$ at $3500 \mathrm{rpm}$; the supernatant was collected in a $50 \mathrm{~mL}$ polypropylene centrifuge tube that was filtered with filters of $0.45 \mathrm{~mm}$. A 0.5 $\mathrm{mL}$ aliquot was added to $1.5 \mathrm{~mL}$ of $0.1 \%$ aqueous formic acid solution. This solution was spiked with $2 \mathrm{~mL}$ of o-phenylenedi- amine at $1 \mathrm{mg} \mathrm{mL} 1$. After a gentle stirring, an aliquot of $1 \mathrm{~mL}$ was transferred into vials and set at the appropriate temperature of $25 \mathrm{C}$ for $24 \mathrm{~h}$, prior to LC-MS/MS analysis. 


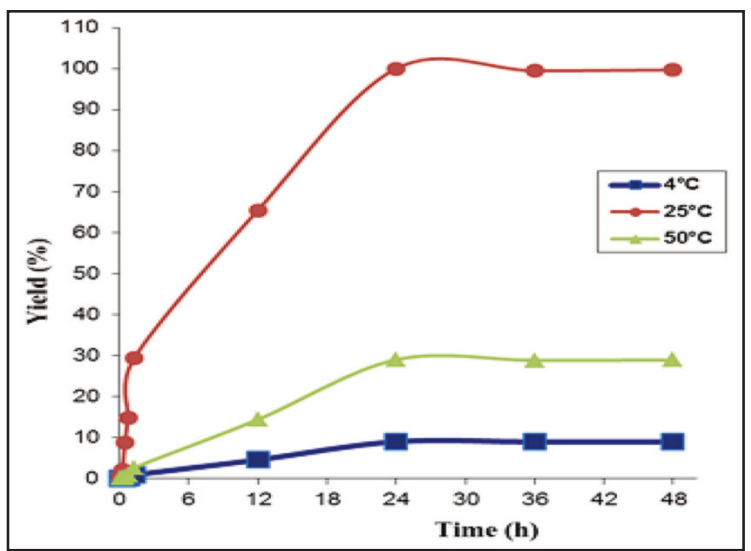

Figure 1. Graphic representation of the yield percentage of the derivatization reaction: kinetic of reaction studied as a function of the time at three different temperatures.

\section{RESULTS AND DISCUSSION}

The Alloxan fragmentation is difficult due to unstable transitions, so the ionization efficiency in ESI is low. The pre-column derivatization with ophenylenediamine, which produces Alloxazine, has provided a better way to detect the analyte in question, due to a greater stability. Alloxazine is the result of reaction between a primary amine and carbonyl groups with formation of a product containing carbon nitrogen double bonds. The reaction is acid catalyzed by hydrochloric acid with elimination of two molecules of water. An alloxan solution was admixed with an excess of derivatizing agent (o-phenylenedi- amine), considering the stoichiometry as known and the yield as unknown. The instrumental results was collected at different time intervals: $5 \mathrm{~min}, 15 \mathrm{~min}, 30 \mathrm{~min}, 45 \mathrm{~min}, 90 \mathrm{~min}$, $12 \mathrm{~h}, 24 \mathrm{~h}, 30 \mathrm{~h}$ and $48 \mathrm{~h}$, in order to evaluating the reaction times. It was found an increasing trend of the yield percentage, up to a maximum value in the $24 \mathrm{~h}$, following by a plateau in the next hours. The effect of the temperature on the yield was $4 \%$ at 4 C, $100 \%$ at $25 \mathrm{C}$ and $29 \%$ at $50 \mathrm{C}$, respectively. Alloxan trace levels were found in $42(24 \%)$ of the analyzed samples, with mean values of $0.95 \pm 0.04$ $\mathrm{mg} \mathrm{kg} 1$ and a range between 0.88 and $1.02 \mathrm{mg} \mathrm{kg}$ 1. Therefore, most of the cake flour are bleached in order to improve their baking per- formance and responding to a wide request for production. The use of chemical oxidizing agents and bleaches were developed to produce quick aging of wheat flour (48 $\mathrm{h}$ ), instead the natural conditions that require several months. Chlorine gas used as bleaching agent may reacts with some proteins in the flour (including the gluten) producing Alloxan as a by-produc. High-gluten flours, such as the cake flour.

\section{CONCLUSIONS}

According to our knowledge (Vadlamudi et al., 1982; Galland \& Senger, 1988; de Oliveira et al., 2005), this work represents the first report on the presence of Alloxan in cake bleached fl our, suggesting a potential risk for consumers due to the application of chlorine gas and other chemicals for baking cakes. The reported UHPLC e MS/MS method was found very sensitive and accurate for the determina tion of Alloxan in wheat fl our starting from $0.85 \mathrm{mg}$ $\mathrm{kg}$. The results obtained show that the fl our bleached with chlorine dioxide and chlorine gas may contain Alloxan as a minor product of a series of oxidation reactions. As a pilot stu dy, further studies are needed with a larger number of fl our samples, in order to understand the real risk for the consumers.

\section{REFERENCES}

Carvalho E.N., de Carvalho N.A.S. \& de Ferreira L.M., 2003. Experimental model of induction of diabetes mellitus in rats. Acta Cirurgica Brasileira, 18: 60-64. http://dx.doi.org/10.1590/S0102-8650200300110 0009

de Oliveira C.A., Luciano E. \& de Mello M.A.R., 2005. The role of exercise on long term effects of alloxan administered in neonatal rats. Experimental Physiology, 90: 79-86. https://doi.org/101113/expphysio 12004028241

Galland P. \& Senger H., 1988. The role of pterins in the photoreception and metabolism of plants. Photochemistry and Photobiology, 48: 811-820. http://dx. doi.org/10.1111/j.1751-1097.1988.tb02896.x.

Pincus G., 2013. Recent Progress in Hormone Research: The Proceedings of the Laurentian Hormone Conference. Elsevier

Suganuma N., Kikkawa F., Seo H., Matsui N. \& Tomoda Y., 1993. Poly (adenosine diphosphate-ribose) synthesis in the anterior pituitary of the female rat throughout the estrous cycle: study of possible relation to cell proliferation and prolactin gene expression. Journal of Endocrinological Investigation, 16: 475-480.

Vadlamudi R.V.S.V., Rodgers R.L. \& McNeill J.H., 1982. The effect of chronic alloxan- and streptozotocin-induced diabetes on isolated rat heart performance. Canadian Journal of Physiology and Pharmacology, 60: 902-911. https://doi.org/10.1139/y82-127 